\section{緒言}

流動層を反応装固として使用する場合、㬝内に掓るる 反応粒子の滞在時間の問題が, 伝熱㧍よび反応流体の流 動状態の問題とともにきわめて重要であることは，いま さらいうまでるない。均一粒径からなる粒子群の滞在時 間については, すでに, 矢木, 国井 ${ }^{5)}$, 神谷 ${ }^{12}$, Amund-

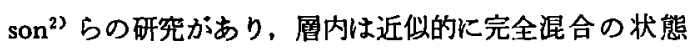
にあることが実証されている。また，不均一粒径の粒子 群についても，矢木，国井 ${ }^{52}$, 古川，大前"2, $\mathrm{Katz}^{32}$ ら の研究があるが，連続式気固相系流動層についてのこの 点に関する研究は少ないようである。筆者らは粒径の異 なる二種の粒子群を混合した試料を使ってこの点につい て実験を行ない，終末速度以下でも層内における大粒子 群の割合が，供給時のそれより增加する傾向のあること を見出した。これに相当する傾向は回分式液固相系およ び気固相系流動層に执いて，それぞれ，古川，大前”， $\mathrm{Katz}^{33}$ らによって钼察されている。

\section{実 験装蜀}

実駼装置は Fig. 1 にその概略を示す。空気は送風機 よりガラス製流量計を通過して整流部で整流されて流動 層に入る。整流部には径が約 5 籷の鉄球と 1 籷の鉛球が 充填され高さ 5 裡の充填風を形成している。整流板は真

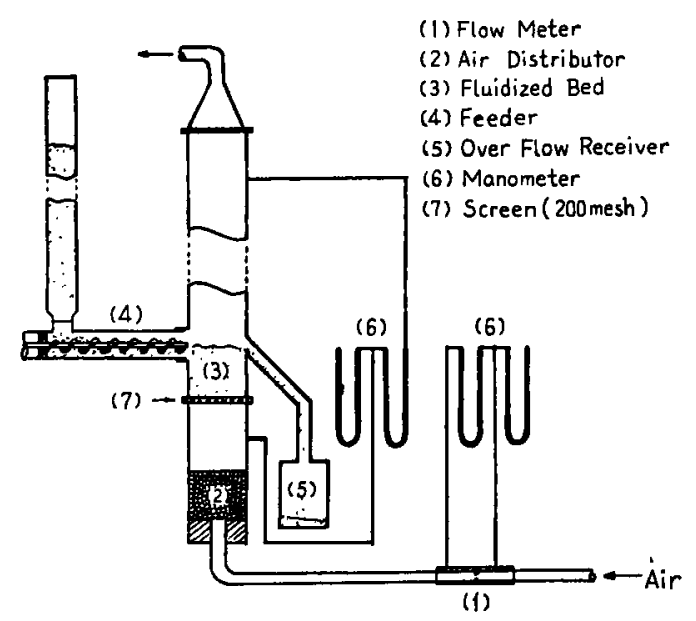

Fig. 1 Experimental apparatus
* 周和 34 年 6 月 5 日受理

** 九州大学工学部応用化学
鍮板に径 1 籷の穴を多数あけ, その上に 200 メッシニの 金銅を取り付けたものを使用した。流動層の径は 58 粍 で整流板から排出口までの高さは 58 粍と 29 粍との二種 類を作成したが，主として前者について実験を行なっ た。粉体の供給はスクリューフイーダーにより行ない, その供給位置は排出口の高さと等しい。またホッパーは 径 3 糧の細長い塔を使用した。これは混合試料を供給す る場合，ホッパーの径が大で下部の円錐部分が大きいと 均一に混合した試料でもその部分で移動しやすい粒子が 先に排出されて混合比が变化する傾向が钼察されたから である。

試料は，砂，粉炭、フクリル樹脂の三種を使用した。 各試料の性質は Table 1 K示す。粒径は，篩目の幾何 平均径, 透過法による粒径, 風篩による粒径などを求め た。石炭を除いて透過法と風節とによる径はよく一致し た。石炭は粉啸過程で扁平な粒子を多く生じたため前記 両者炕よって求めた径が一致しなかったと思われる。こ こでは代表径として風節によって求めた径を採用した。

\begin{tabular}{|c|c|c|c|c|c|c|}
\hline & Table 1 & \multicolumn{4}{|c|}{ Properties of samples } & \multirow[b]{2}{*}[\mathrm{cm}/\mathrm{sec}]{} \\
\hline & Sample d & $\begin{array}{c}\rho_{p} \\
\text { density } \\
{\left[\mathrm{g} / \mathrm{cm}^{3}\right]}\end{array}$ & $\underset{[\mu]}{(\phi d) \times 10^{4}}$ & {$\left[-w^{w .0}\right.$} & $\begin{array}{r}\text { Sieve } \\
\text { [mesh] }\end{array}$ & \\
\hline S 1 & Sand & 2.63 & 320 & 0.0 & $32 \sim 42$ & 245 \\
\hline S 2 & $"$ & $"$ & 170 & 1.0 & $48 \sim 80$ & 124 \\
\hline C 1 & Coal & 1.80 & 286 & 0.0 & $32 \sim 42$ & 170 \\
\hline C 2 & $"$ & $"$ & 205 & 1.0 & $42 \sim 60$ & 113 \\
\hline A 1 & Acryl Resin & n 1.04 & 990 & 0.0 & $16 \sim 20$ & 400 \\
\hline A 2 & $"$ & $"$ & 740 & 1.0 & $20 \sim 24$ & 310 \\
\hline Sm 1 & Sand & 2.63 & (262) & 0.25 & $32 \sim 80$ & - \\
\hline Sm 2 & $"$ & $n$ & $(222)$ & 0.50 & $"$ & - \\
\hline Sm 3 & $n$ & $"$ & (192) & 0.75 & $"$ & - \\
\hline
\end{tabular}

\section{均一粒彺粒子による残余瀑度曲楾}

笑験方法は神谷 ${ }^{1)}$ の方法と大体同じで，標示粒子とし て重クロム酸カリを使用した。種々の流速について実験 乙 Fig. 2 を得た。矢木，国井52，神谷1) らの結果と同 じく層内の粒子は完全混合の状態にあるとみなせる。

\section{保持昷と流速との関係}

实験方法は流動化させながら試料を一定速度で供給し 層内が定常状態になったところで粉体および空気の供給 を同時に止めて層内粒子を取り出し重量を測定した。な 


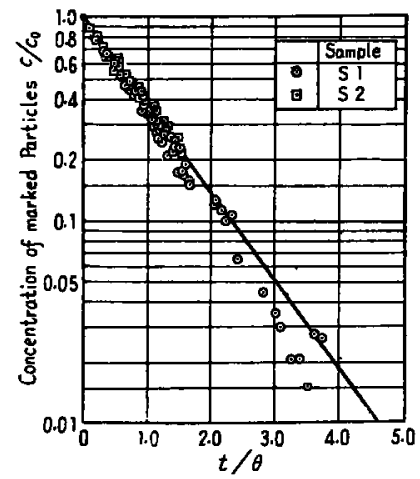

Fig. 2

Distribution of residence time for particles in fluidized bed

沶混合試料を使用する場合は試料が均一な混合状態で㬝 内に供給されるよ5注意した。流動層の排出口の高さが 整流板から 58 粍の流動層を使用した場合は保持量は流 速が增加すると単調に減少した。しかし排出口の高さが 29粍の流動層では風高が排出口上り高くなることがあり 前記の関係は必ずしも存在しなかった。しかしながら層 内の平均粒子密度と流速との間には一定の関係が存在 し, その結果仕 Fig. 3 (a) （c）に示す。

Fig. 3 (a) および (c) は砂を試料とした場合で， と むに混合試料の層内平均粒子密度が二種の均一粒径粒子 による結果の中間の值となり，大粒子の多い試料ほど大 きくなっている。また粉体供給速度の影部は実験範囲内 $(F=20 \sim 36 \mathrm{~g} / \mathrm{min})$ では顕著でない。Fig. 3 (c) では 流動層の高さが排出ロ上り高くなり，Fig. 3 (a) の場 合 (流動層高さと排出口高さが等しい) に比して粒子密 度が大きい。各記号を点線で示したるのは流動開始速度 を示す。

\section{首内平均比表面獈とレイノルス数}

前節の結果は平均比表面積とレイノルズ数を使って, よく整理された。その結果は Fig.4 (a) に示す。なお 混合試料の平均粒径は比表面積径を使用した。すなわち

$$
1 /(\phi d)=w_{1} /\left(\phi_{1} d_{1}\right)+w_{2} /\left(\phi_{2} d_{2}\right)
$$

たたしし，dは粒径，申は形状係数，wは重量分率，添字 lは大粒子，添字 2 は小粒子を表わす。ここでは， $w_{2}=1$ である。また，平均比表面稫およびレイノルズ数 はおのおの次式で示す。

$$
\begin{aligned}
a & =6(1-\varepsilon) /(\phi d) \\
R e & =\rho(\phi d) u / \mu(1-\varepsilon)
\end{aligned}
$$

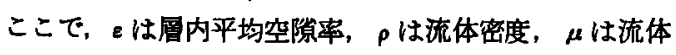
粘度, $u$ は流体の層内平均空筒速度である。

Fig. 4 (a) К扗いて，飛び出し粒子の少ない範睡で は，すへての試料について次の実験式が得られた。

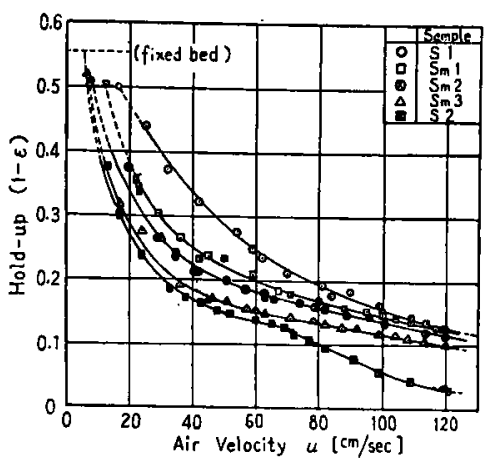

Fig. 3 (a) Effect of gas velocity on fluidized bed density (Hold-up) $L / D=1.0$, (sand)

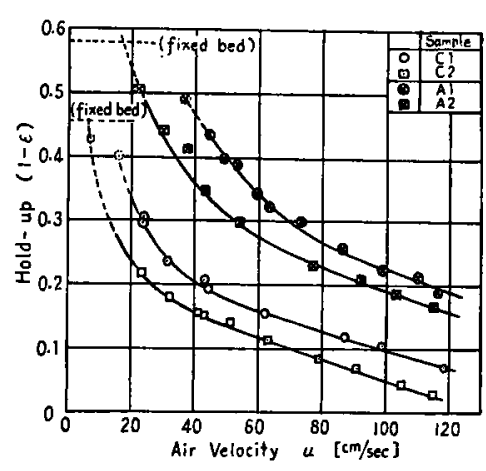

Fig. 3 (b) Effect of gas velocity on fluidized bed density (Hold-up) $L / D=1.0$, (Coal, Acryl resine)

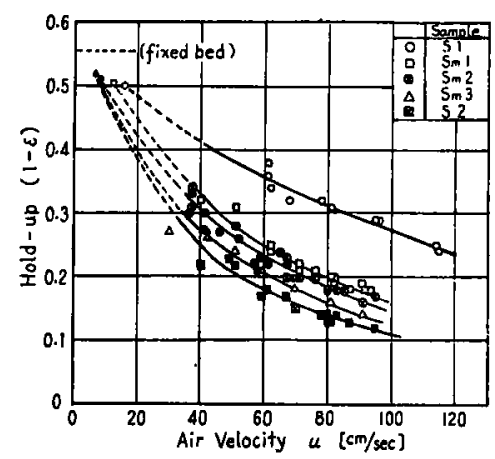

Fig. 3 (c) Effect of gas velocity on fluidized bed density (Hold-up) $L / D=1 / 2$, (Sand)

$$
a=k \sqrt{\rho_{p}}(R e)^{-0.38} \quad\left(R e \leq R e_{\infty}\right)
$$

ただし，kは常数， $\rho_{p}$ は粒子の密度を表わす。Fig. 4 （a）で（1）は䅉高が排出口より高くなる場合，(2)は層 高が排出口の高さと大体等しい場合である。(1) のとき は排出管内に粒子の堆積が観察された。このために粒子 は排出を妨害され，䅉内の粒子密度が増加する。これは， 
流体が管内を流れている 場合に，その管内に抵抗 を入れるとその部分の前 欧が增加する，すなわち 流体密度が增加する現象 と類似している。また， (2) の S 2 の試料括よび C 2 の試料に見られるよ 5 K，粒子の飛び出し現 象が生ずるところでは直 線の勾配方変化する。こ れはつきのように考壳ら れる。い主, 層内の流速 が粒子の終末速度より大 きく均一粒径の全粒子が 飛び出して，しかも層内 の粒子密度は均一になっ

ているとすれば，層内の平均比表面㮴は近似的につきの 上5に示される。

$$
a=\frac{6(1-\varepsilon)}{(\phi d)}=\left(\frac{6}{\phi d}\right) \frac{f}{A p_{p}\left(u-u_{\infty}\right)}-
$$

ただし， $A$ は流動層の断面積， $f$ は粒子の供給速度を示 す。S 2 の試料について（2）式で計算した結果を Fig. 4 （b）に示す。他の均一粒径試料についても同様な曲線が 得られる。また，混合試料についても粒子間の相互作用 がない理想状態を仮定すると比表面積は加成性が成り立 ち、したがって均一試料の場合と同様な結果が予想され る。このよ5な Fig. 4 (b) の理想曲線から, 粒子の飛 び出し現象が生ずる場合には直線の勾配が急に变化する ことは予測できる。

\section{粒径の翼なるニ 種の粒子群の混 合比の变化}

実験方法は㬝内が定常 状態になってから粉体お。 よび空気の供給を同時に 止めて層内粒子を取り出 し標泘笠で分離して各粒 径粒子群の重量を測定し て漉合比の变化を調へ た。その結果を Fig. 5 (a) および (b) に示す。 供給試料の混合比と層 内での混合比との差は流 速が增すととるに增大す

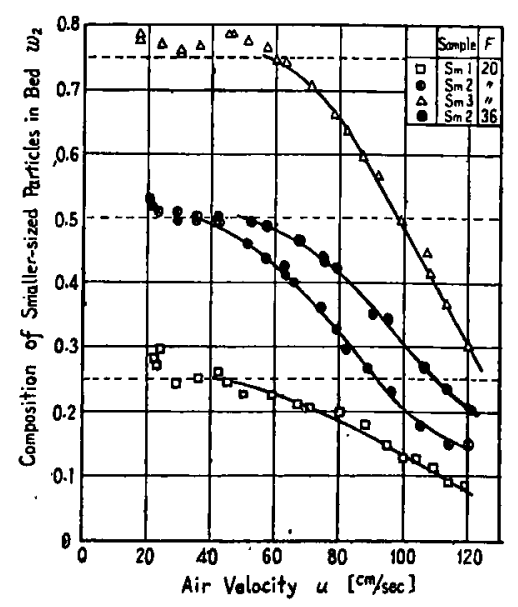

Fig. 5 (a) Effect of gas velocity on the composition of smaller-sized particles in bed, $L / D=1.0$

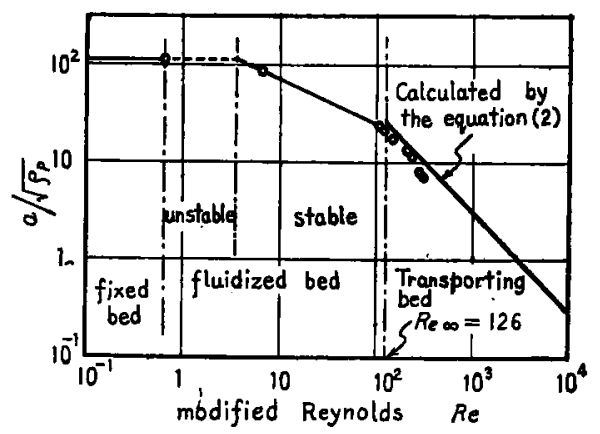

Fig. 4 (b) $\quad a / \sqrt{\rho_{p}}$ vs. modifled Reynolds number for Sample $S 2$.

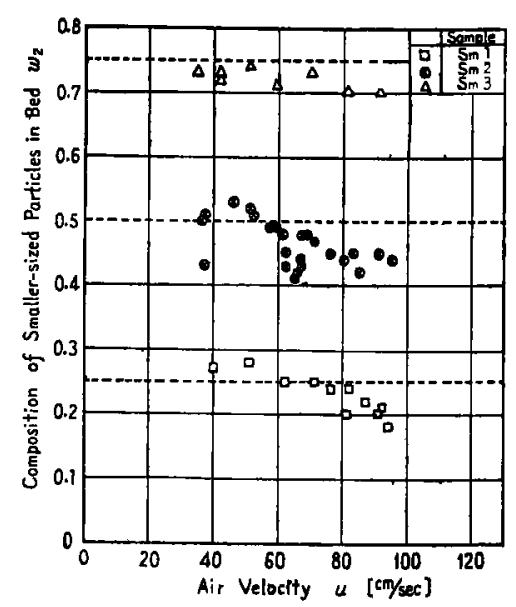

Fig. 5 (b) Effect of gas velocity on the composition of smaller-sized particles in bed, $L / D=1 / 2$ 
る。しかし流動䁬の高さが排出口より高くなる場合には

Fig. 5 (b) に示すよ 5 に混合比の栾化は流速が增して す顕著ではない。これより層上部に小粒子が多く存在す る傾向が予測される。また（a）から粉体供給速度が増 すと混合比の変化が小さくなることが判る。

これらの点に関しては今後さらに吟味する予定であ る。

\section{總 括}

連続式気固相系流動層における粒子の滞在時間分布を 知る目的から，層内の粒子保持量と流速の関係，扰上び 混合試料について層内の小粒子濃度と流速の関係などを 調べ次の結果を得た。

（1）啳内の粒子密度は流速の增加とともに減少し, その結果は層内平均比表面積とレイノルズ数で整理され る。

（2）粒径の異なる二種の粒子群からなる混合試料で は流速を増加すると層内の大粒子湄度が増加する。粉体 の供給速度が小さいほどこの傾向が顕著である。また流 動層高さが排出口の高さより高くなるとこの傾向は減退 する。この結果から層上部に小粒子が分布されやすいこ とが予测できる。

\section{Nomenclatures}

$a:=\frac{6(1-\varepsilon)}{(\phi d)}$, mean specific contact area $\left[\mathrm{cm}^{-1}\right]$

$A$ : cross sectional area of fluidized bed $(=26.5)$ $\left[\mathrm{cm}^{2}\right]$

$c:$ concentration of the marked particles $[-]$

$d$ : mean particle diameter [cm]

$D$ : fluidized bed diameter $[\mathrm{cm}]$ $f:$ feed rate $[\mathrm{g} / \mathrm{sec}]$

$K$ : empirical constant (=136)

$L$ : height of overflow pipe measured from the screen

$[\mathrm{cm}]$

$R e:=\rho(\phi d) u / \mu(1-\varepsilon)$, modified Reynolds number

[-]

$t$ : time

[sec]

$u$ : mean superficial air velocity $[\mathrm{cm} / \mathrm{sec}]$

$w:$ weight fraction [-]

$W$ : total weight of particles in fluidized bed $[\mathrm{g}]$

$\varepsilon:$ nean porosity in fluidized bed $[-]$

$\theta:=W / f$, mean residence time of particles in fluidized bed [sec]

$\mu$ : fluid (air) viscosity $[\mathrm{g} / \mathrm{cm} \cdot \mathrm{sec}]$

$\rho$ : fluid (air) density $\left[\mathrm{g} / \mathrm{cm}^{3}\right]$

$\rho_{p}$ : particle density $\left[\mathrm{g} / \mathrm{cm}^{3}\right]$

$\phi$ : shape factor [-]

Subscripts

0 : initial

1: larger sized particles

2 : smaller sized particles

$\infty$ : terminal

\section{Literatures cited}

1) Kamiya, Y. . Chem. Eng. (Japan), 19, 412 (1955)

2) Kasten, P. R. and Amundson, N. R. : Ind. Eng. Chem., 42, 1341 (1950)

3) Katz, H. M. : "Studies of Particle Size Distribution in Fluidized Bed" (U. S. A., A. N. L. Report, 5725, 1957)

4) Omae, T. and Furukawa, J. : J. Chem. Soc., Japan, Ind. Chem. Sect., 56, 727 (1953)

5) Yagi, S. and Kunii, T. : Chem. Eng. (Japan), 16, 283 (1952)

\title{
Residence Time of Particles in Fluidized Bed
}

\author{
F. Nakashio* and W. Sakai*
}

To obtain information concerning residence time of particles in fluidized bed, the effects of gas velocity on hold-up and concentration of smaller-sized particles in fluidized bed were observed and the following results were obtained.

1) Particle hold-up in bed decreases as gas velocity increases. (See Fig. (a) (c)). Specific contact area is correlated to modified Reynolds number, as shown in Fig. 4 (a) and (b).

2) Fluidized bed consisting of particles of two sizes tends to give a higher percentage of coarse particles than that given by the feed. This tendency becomes remarkable with the increase of gas velocity and decrease of feed rate, as shown in Fig. 5 (a). But it diminishes in case the fluidized bed is placed higher than $L$, the height of overflow pipe, as seen in Fig. 5 (b).

* Department of Applied Chemistry, Kyushu University 